\title{
PATRIMONIO Y PAISAJE: DOS FORMAS DE ENSAMBLAR NATURALEZA Y CULTURA EN LA CUENCA DEL RÍO VALDIVIA, SUR DE CHILE
}

\author{
LANDSCAPE AND HERITAGE: TWO WAYS OF ASSEMBLING CULTURE AND \\ NATURE IN THE RIO VALDIVIA BASIN, SOUTH OF CHILE
}

\author{
Juan Carlos Skewes ${ }^{1}$, Debbie Guerra ${ }^{2,3}$ y Christian Henríquez $^{3}$
}

\begin{abstract}
La relación entre paisaje y patrimonio se aborda mediante la comparación de la percepción ambiental de residentes de dos comunidades de la cuenca del río Valdivia-Milleuco, en la cordillera, y Las Coloradas, en la costa. La comparación fue hecha a partir del análisis de contenido del registro de conversaciones grupales y sus resultados fueron contrastados con las características del ambiente, sugiriéndose una correlación significativa entre percepción del medio, ecología local y patrimonio. Esta correlación pone de relieve la matriz cultural que organiza la percepción, condicionando las oportunidades que ambas comunidades tienen de pervivir en su medio, las que están dadas por la valoración de los aspectos percibidos del entorno que, a través de la práctica colectiva, son patrimonializados, constituyéndose en hitos no solo para la identidad local, sino además para la conservación del medio.

Palabras claves: paisaje, patrimonio, cuenca del río Valdivia, Mapuche.
\end{abstract}

The relation between landscape and heritage is approached from the comparison between the environmental perception of the members of two communities of the river Valdivia basin - Milleuco in the Andes range and Las Coloradas in the coast. The comparison was carried out using content analysis of the transcript of group conversations. These results were contrasted with the characteristics of the environment, finding a strong correlation between environmental perception, local ecology and heritage. This correlation highlights the cultural pattern that organizes the residents' perception, influencing the chances that the communities have of surviving in their environments. Such chances are given by the valorization of the perceived features of the environment which, by means of collective practice, are turned into part of their heritage, turning them into landmarks not only for the local identity but for the conservation of nature.

Key words: Landscape, heritage, river Valdivia basin, Mapuche.

Un elemento fundante en la definición de paisaje ha sido la mirada, ese hábito moderno de constituir en belleza escénica una circunstancia cautivante a los sentidos. El cautiverio de los sentidos, no obstante, bien puede significar el congelamiento de a quienes se percibe como parte de la escena, proceso de esencialización representacional que ha sido descrito como "congelamiento metonímico", esto es, cuando un aspecto de la vida de la gente viene a representarla como un todo (Clifford 1997; Rosaldo 1991). El tránsito necesario, a partir de este punto, es pasar del hábito al habitar, de la mirada escénica a la mirada protagónica y de la experiencia visual a la experiencia sensorial en general, tensionando así las imposiciones externas y favoreciendo la apropiación efectiva del entorno por sus protagonistas (Ingold
1993). Más que proclamar la autoridad del experto y su derecho para definir lo patrimonial, esta alternativa pide hurgar entre las prácticas sociales que tienen un efecto patrimonializador. La búsqueda de hitos estructurantes de la cosmovisión permite identificar los elementos constitutivos de la identidad colectiva y relacionarlos con la ecología local. Subyace en este planteamiento el supuesto según el cual la imbricación espacial de tales contenidos sirve de asiento para ejercer una acción patrimonializadora. Este giro permite discernir nuevos contornos en las dimensiones patrimoniales del paisaje y, con ello, tornar exigibles reconocimientos ausentes en la experiencia de las comunidades locales, promoviendo de esta manera transformaciones políticas locales y regionales que les sean favorables.

\footnotetext{
1 Departamento de Antropología, Universidad Alberto Hurtado, Cienfuegos 41, Santiago, Chile. jskewes@uahurtado.cl

2 Instituto de Salud Sexual y Reproductiva, Universidad Austral de Chile, Independencia 641, Valdivia, Chile. dguerra@uach.cl

3 Centro de Estudios Ambientales, Universidad Austral de Chile, Independencia 641, Valdivia, Chile. christianhen@ gmail.com
} 
Este planteamiento importa varias definiciones: por una parte, entender naturaleza y cultura como una simbiosis (Rozzi 1997). Esta comprensión invita a diluir las fronteras de fenómenos que, en el contexto habitual de pensamiento se mantienen separados (Massey 2005). En segundo término, se diluye también la distinción entre material e inmaterial, dicotomía que refleja más los hábitos de pensamiento que la realidad de las cosas: cualquier hecho de la experiencia cotidiana es una síntesis o trayectoria en que se engarzan los actantes humanos y no humanos (Latour 1999). En tercer lugar se pone en tela de juicio la distinción entre el reclamo consciente por el patrimonio y la práctica menos estentórea cuyo efecto es el de patrimonializar. El patrimonio visto como un anclaje robustece la simbiosis entre comunidad y naturaleza, favoreciendo la apropiación local del paisaje como un bien común, esto es, tornarlo en soberano. La definición del patrimonio, desde esta perspectiva, constituye un hecho político cuyo ejercicio reclama autonomía para quienes lo viven (Bonfil Batalla 1991).

Aquí se entiende el patrimonio cultural tangible e intangible como una síntesis paisajística entre componentes no humanos y humanos, donde los primeros son asumidos por los segundos como estratégicos para la afirmación de su identidad, en tanto parte de sus prácticas económicas, sociales o políticas (Guerra y Skewes 2008). Esta definición especifica la propuesta de Bonfil Batalla (1991), según la cual el patrimonio se refiere al:

acervo de elementos culturales, tangibles unos, intangibles los otros, que una sociedad determinada considera suyos y de los que echa mano para enfrentar sus problemas (de cualquier tipo, desde las grandes crisis hasta los aparentemente nimios de la vida cotidiana); para formular e intentar realizar sus aspiraciones y sus proyectos; para imaginar, gozar y expresarse (Bonfil Batalla 1991:90).

Los elementos patrimoniales adquieren su sentido más allá de su declaratoria como tales o de los empeños que se hagan para su reconocimiento: este sentido se desprende de su relación con el mundo vivido y con el paisaje a que contribuyen a formar. Si la lugarización es una manera de construir el pasado, una manera de hacer historia humana, es también una forma de construir tradiciones sociales y, en el proceso, de establecer identidades sociales y colectivas (Basso 1996; González 2004). De especial significado es reconocer el vínculo emocional que las comunidades establecen con su territorio. El concepto de topofilia propuesto por Tuan (1974) apunta en este sentido. Se añaden en esta perspectiva las dimensiones materiales paisajísticas y emocionales implicadas por cualquier proyecto social: el mundo no humano es tenido como depositario activo de la presencia humana, a la vez que el componente humano es entendido como prolongación necesaria de las cosas que le rodean (Criado 1999). Esta definición plantea el desafío de vincular el recurso patrimonial al espacio de vida de un grupo determinado y, al mismo tiempo, relacionarlo con su identidad y práctica social (De Certeau 1984; Strang 2006). Una síntesis paisajística con valor patrimonial, esto es, que tenga la capacidad de preservar los componentes no humanos del paisaje para su futura interlocución con la comunidad humana, no es automática.

Este artículo explora la síntesis paisajística que se produce entre naturaleza y cultura en términos de su potencial patrimonializador. Naturaleza y cultura son parte de procesos históricos y se imbrican entre sí mediante diferentes configuraciones paisajísticas (Farina 2000). Tales composiciones pueden ser examinadas a través, por una parte, de la biodiversidad local -definida como la variabilidad de organismos vivos de cualquier fuente, incluidos los ecosistemas terrestres y marinos y otros ecosistemas acuáticos y los complejos ecológicos de los que forman parte (Naciones Unidas 1992)- y, por la otra, de la percepción expresada por medio del lenguaje y materializada por la vía de las prácticas sociales, entendiendo que la percepción es un ejercicio práctico de involucramiento en el mundo (Ingold 2011).

En este artículo se adopta la perspectiva propuesta por Gibson (1979, citado por Ingold 2011) para comprender la percepción, la que es tenida no como una conquista de la mente, sino más bien del organismo en su movimiento por el mundo. De aquí que las cosas no se revelen en tanto tales a los organismos, sino por la forma como se les ofrecen para su propio despliegue y es, justamente, por medio de atender y responder a estos "ofrecimientos" (affordances) como los practicantes llegan a conocerlas. Semejante movimiento se corresponde con lo que las personas hacen y dicen cotidianamente, contribuyendo a crear, fortalecer y transformar aquellos sistemas culturales que les 
moldean (Ortner 1984). Estas acciones trasuntan las tensiones políticas que supone la relación entre los actores individuales o colectivos y las estructuras sociales, culturales, ambientales y económicas que organizan sus vidas.

Uno y otro aspecto, biodiversidad y percepción son procesos históricos $\mathrm{y}$, por lo tanto, permiten vincular la ecología política (Escobar 1999a, 1999b) con la ecolingüística (Basso 1996; Mülhaüsler y Peace 2006) y la ecología simbólica (Biersack 1999; Descola 2013). Hay en uno y otro aspecto importantes tradiciones en la antropología, las que se entrecruzan en el momento que las visiones sistémicas comienzan a ser confrontadas por quienes reconocen en el agente y en las acciones nuevas oportunidades para la interpretación social (Ortner 1984). En el caso de la lingüística el énfasis en la pragmática ha permitido esclarecer cada vez más la relación dialéctica entre mundo y lenguaje (Hymes 1972) al modo como se plantea desde la ecolingüística. Desde este punto de vista el lenguaje está interconectado con el mundo: lo construye a la vez que es construido por él (Mülhaüsler y Peace 2006).

En el campo de la ecología, a su vez, las perspectivas adaptativa y ecosistémica han cedido espacio a visiones históricas que se hacen eco de las pulsiones derivadas de las interacciones entre procesos globales y locales. La prolífica producción intelectual surgida a partir de los trabajos de Escobar $(1995,1998,1999 b)$ y Leff (2003), entre muchos otros, da cuenta de la reconfiguración del paisaje local fruto de la imposición de nuevos órdenes mundiales: la instalación de los regímenes de naturaleza, siguiendo la terminología de Escobar (1999a), no puede sustraerse a las relaciones globales que determinan su curso, tal como se desprende de la obra seminal de Eric Wolf (1987 [1982]. El desafío planteado consiste en vincular, a través del estudio etnográfico, ambas tradiciones.

Las formas de concebir la relación entre los seres humanos y la naturaleza responden a determinantes históricas y culturales. En términos gruesos, y con muchas variaciones locales, se pueden distinguir aquellas visiones que sacralizan la naturaleza de aquellas que la conciben como un medio para satisfacer las necesidades de reproducción social de un grupo determinado y de otras que ven, en la naturaleza, un medio para generar ganancias. En el primer caso, Gudynas (2011) sugiere hablar de la naturaleza como la "madre tierra". En el segundo,
Gudeman (2008) habla de una economía de la casa, y, en el tercero, de la corporación, reservando Gudynas (2011) el concepto de la "naturaleza como capital" para esta visión que se vuelve hegemónica en el capitalismo avanzado.

La argumentación desarrollada en este artículo toma como referencia las prácticas culturales y percepciones ambientales de los residentes de dos comunidades de la cuenca del río Valdivia, cuya comparación permite ilustrar el supuesto según el cual mayores niveles de apropiación comunitaria de la naturaleza se traducen en un ejercicio patrimonializador más intenso que asegura mejores recaudos para la conservación de la biodiversidad y mayores niveles de autonomía de la comunidad en relación con otros actores.

En esta hipótesis se resumen algunos planteamientos avanzados por la investigación en el campo de las relaciones entre el ser humano y la naturaleza vinculando tales líneas de un modo ausente en la literatura. Los principales hallazgos de esta investigación se nutren de los aportes que, por distintas vías, han subrayado: (i) El valor crucial que tanto el conocimiento local como la memoria cultural tienen para la conservación de la biodiversidad (Nazarea 2006), (ii) el papel que desempeña el paisaje en la constitución de identidades individuales y colectivas (Basso 1996; Strang 2006), (iii) el papel que cabe a las comunidades en la conservación de la biodiversidad, a pesar de los drenajes impuestos por los procesos modernizadores (Zimmerer 2003 en Nazarea 2006), (iv) la importancia de las perspectivas locales para orientar el desarrollo sostenible (Vessuri 2004), (v) la mutua determinación de lenguaje y ambiente (Mülhaüsler y Peace 2006), y (vi) la constatación de que el conocimiento y la experiencia de la naturaleza producen efectos benéficos para los grupos humanos (Russell et al. 2013). Sin embargo, el puente entre los procesos cognitivos expresados mediante el lenguaje y de las prácticas sociales, por una parte, y de los procesos políticos e históricos demandan aproximaciones vinculantes que en este artículo son exploradas. Los resultados de la presente investigación avanzan en comprender la articulación entre procesos políticos y cognitivos proponiendo una aproximación metodológica que aspira a allanar un camino que demanda a futuro mayor inversión académica para ser recorrido a cabalidad.

A continuación se describe, en primer lugar, la propuesta metodológica involucrada en la realización de este estudio, para luego identificar las modalidades 
como se articula la síntesis paisajística en las dos comunidades tanto a nivel del lenguaje como en términos de las características de la ecología local. Sobre esta base es posible generar la discusión acerca de las posibilidades de constituir la naturaleza en parte del patrimonio y examinar las oportunidades y restricciones que tanto el marco ecológico como las concepciones culturales establecen en relación con las prácticas colectivas. Se concluye señalando la necesidad de expandir el lente que se usa para entender el patrimonio, subrayando la conveniencia de favorecer las condiciones necesarias para desplegar una acción que se traduzca en un mejor recaudo tanto de la autosuficiencia local como de la biodiversidad.

\section{Metodología para la Comparación Socioambiental de Dos Comunidades de la Cuenca del Río Valdivia}

La propuesta metodológica se basa en la comparación socioambiental de prácticas sociales en dos comunidades usando técnicas de la investigación acción y de observación directa para el registro y aplicación del análisis de contenido a la información generada por esa vía. Milleuco y Las Coloradas son comunidades pertenecientes a la misma cuenca hídrica, en este caso la del río Valdivia, pero geográficamente ubicadas en diferentes niveles altitudinales (Figura 1). Se las ha escogido para fines de comparación toda vez que representan dos modalidades diversas de habitar un territorio: una -Milleuco-inspirada por la cosmovisión mapuche, la otra -Las Coloradas- por la cultura chilena de un pequeño grupo colono rural. En ambos casos se trata de tierras marginales, de escasa conectividad y que, por lo mismo, han permitido, con distintos niveles de éxito, la reproducción de una economía doméstica de autosubsistencia.

Milleuco se emplaza en las laderas occidentales de los lagos Calafquén y Panguipulli. Se trata de una veintena de familias mapuches que, en el contexto de la reorganización territorial de la región, se vieron desplazadas desde las cotas inferiores ocupadas por la expansión maderera. Los procesos de relocalización experimentados por las comunidades cordilleranas de la zona se remontan a los comienzos del siglo XX (Millanguir 2007). La penetración, motivada principalmente por los afanes de colonización de los gobiernos chilenos como por la actividad forestal extractiva son los principales agentes de transformación territorial en ese período (Rehren 1908) (de ello da cuenta el testimonio de Aurelio Díaz Meza (2006 [1907] en su crónica acerca del Parlamento de Coz-Coz celebrado en 1907 con el afán de proteger los derechos de las poblaciones indígenas en un contexto de expansión chilena). La consolidación precaria de la gran propiedad rural entre los años 1920 y 1960 crea una situación que permite a las comunidades indígenas sobrevivir en tierras de refugio, articulando la autoproducción con el trabajo asalariado. La tercera fase identificable está marcada por el desarrollo de la industria maderera y su estatización con la creación del Complejo Maderero de Panguipulli, época de efervescencia social con un importante aumento de la población obrera (Rivas 2006). La culminación de este período conduce a una etapa donde la industria del turismo y la concentración de propiedades recreacionales conviven con la población originaria en un equilibrio amenazado por conflictos emergentes asociados al desarrollo de proyectos hidroeléctricos (Skewes et al. 2011). Actualmente, las familias de este territorio combinan la pequeña agricultura con la prestación de servicios personales y venta de fuerza de trabajo en el área colindante (Skewes et al. 2012).

Las Coloradas, a su vez, se ubica $107 \mathrm{~km}$ río abajo: se trata de un pequeño caserío en la sección sur de la Isla del Rey, la que está rodeada por los ríos Valdivia, Tornagaleones y Futa. La historia de este territorio está marcada por una antigua presencia colonial, ligada al aparato defensivo levantado por la Corona española en el siglo XVII frente a la amenaza de invasión holandesa, la que nunca llega a producirse. La isla fue despojada a los indígenas y entregada a título individual a un colono español. Parte de la producción local fue destinada al abasto del puerto cárcel de Corral. La pesca, la pequeña agricultura y el trabajo de la madera fueron las bases sobre las que se sostuvo una pequeña población en la isla, agrupada en dos caseríos: Las Coloradas, nombre que la leyenda popular atribuye a la descendencia dejada por unos navegantes holandeses, y Carboneros (Subiabre et al. 1997). La presencia, en el siglo XX, de los Altos Hornos de Corral, entre 1905 y 1958, estimuló la producción de carbón vegetal, lo que confiere el nombre al caserío homónimo.

A Las Coloradas se accede tras unos 45 minutos de navegación en lancha desde Niebla por el río Tornagaleones. Hay 36 familias activas en la localidad y un número indeterminado de personas 


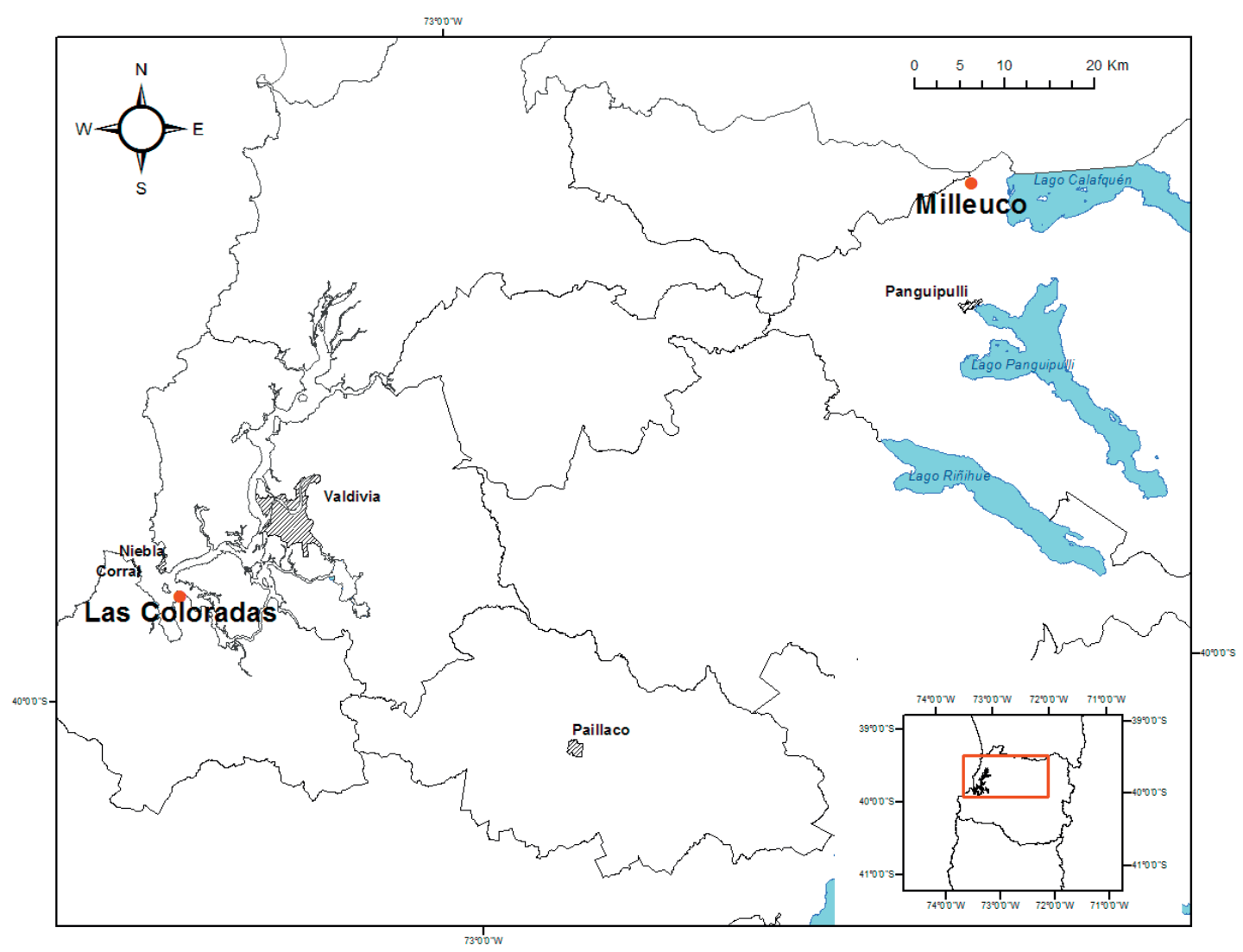

Figura 1. Mapa de ubicación de Las Coloradas y Milleuco (diseño de Jessica Castillo Mandujano). Location map of Las Coloradas and Milleuco (drawing Jessica Castillo Mandujano).

que vive ahí en épocas específicas del año o hace visitas ocasionales a sus casas. De acuerdo con el censo de 2002, la localidad de Las Coloradas contaba con una población de 87 personas, 43 mujeres y 44 hombres, repartidos en 40 viviendas (Instituto Nacional de Estadísticas 2013). En los años ochenta, la llegada de la actividad forestal será decisiva en la vida de la isla, quedando las dos poblaciones enclaustradas por extensas plantaciones de pino y eucaliptus. La principal actividad de los residentes actuales es la pesca artesanal y recolección de algas marinas combinada con agricultura menor, el turismo y los servicios prestados a la empresa forestal. Rodeando la localidad se encuentran los terrenos de la Forestal Valdivia, cuyas plantaciones de pino y eucaliptus cubren un gran porcentaje de área de la Isla del Rey, reduciendo la presencia de bosque nativo, el cual al estar en su mayor parte dentro de los terrenos de la forestal, está en constante amenaza de desaparición.
Una forma de comparar la experiencia vivida de las comunidades de Milleuco y Las Coloradas es, de acuerdo a las orientaciones de Gudeman y Rivera (1990), prestando atención a las conversaciones de sus habitantes, a las formas como la naturaleza se ha encarnado en el verbo (y también a la forma como el verbo se ha encarnado en la naturaleza). Para hacerlo se constituyeron jornadas de conversación al modo de la investigación acción, contando con el consentimiento de las y los participantes para grabar las sesiones, tras lo que se procedió a analizar el registro obtenido. Este material se complementó con actividades de campo que incluyeron observaciones directas en terreno, conversaciones casuales con los miembros de ambas comunidades y entrevistas en profundidad.

Los resultados presentados se inscriben en el marco de una investigación de campo desarrollada entre los años 2009 y 2012 en la cuenca del río Valdivia. Las localidades involucradas constituyeron 
estaciones de trabajo a las que, en total, se destinaron dos meses de trabajo. Durante ese período se establecieron los contactos iniciales, se prepararon y realizaron los grupos de discusión y se llevaron a efecto las entrevistas en profundidad ${ }^{1}$.

En el caso del presente estudio, el material permitió identificar nueve nodos o grandes temas de interés para la comunidad: Agua, Tierra, Contaminación, Catástrofes, Especies, Cosmovisión, Actividades económicas, Organización social y Relación con el Estado. En torno a estos códigos se agruparon los 73 subcódigos empleados. Para la comunidad de Milleuco se generaron 46 subcódigos los que se aplicaron en relación a 169 frases del registro; para Las Coloradas, a su vez, se usaron 48 subcódigos aplicados a un total de 166 frases. El análisis de estas conversaciones se contrastó, a su vez, con las características de la ecología local, establecidas a partir de los usos del suelo y presencia de flora y fauna en un radio de tres kilómetros, tomando como centro a cada comunidad.

El carácter discreto de esta categorización responde a fines analíticos y, naturalmente, no se condice con la visión teórica que busca relevar los entrelazamientos que se producen entre estas dimensiones. Sobre esta base fueron definiéndose las unidades menores (o categorías hijos), las que emergen desde las conversaciones mismas y que van precisando las unidades de registro que proporcionan la información en que se sostiene la argumentación aquí esgrimida. Naturalmente que, como aconseja la literatura, tal registro requiere -como se ha hechode una adecuada contextualización.

La comparación de las conversaciones sostenidas en las comunidades de Milleuco y Las Coloradas, como se analiza más adelante, ofrece la oportunidad de especificar las características de los procesos de simbiosis entre comunidad y ambiente y las oportunidades que se ofrecen a los procesos de patrimonialización desde el punto de vista de la ecología local.

\section{La Síntesis Paisajística}

El paisaje se instala en la confluencia entre naturaleza y comunidad y no puede revelarse sino en relación con el sujeto o comunidad que lo constituye. Es naturaleza, sin duda, pero naturaleza al modo que es vivida por los seres humanos que la habitan. Tal es la constatación que puede desprenderse de los resultados que a continuación se presentan.
La comparación, como se ha señalado, se hace a partir de las características del medio local de cada una de las comunidades y la percepción por ellas generada, lo que permite hacer un análisis en el que se decantan los contenidos que históricamente marcan las formas de inervación de la comunidad con su medio y con su región. La percepción local del paisaje se desprende de lo que se hace y dice en relación con el medio del que se es parte. Una primera indicación acerca de las modalidades de inserción propia de cada comunidad se relaciona con los grandes temas emergentes en el diálogo comunitario. En la Figura 2 se advierten las principales diferencias a partir de las que se estructuran las percepciones acerca de la naturaleza y la sociedad en ambas comunidades.

En el caso de Milleuco, en la cordillera mapuche, los temas de la cosmovisión, de las especies arbóreas, la tierra y los animales se constituyen en los ejes vertebradores, mientras que en Las Coloradas, las actividades económicas, la contaminación y las especies marinas son las de interés principal. Al vincular los códigos con los usos asociados a ellos queda de manifiesto la forma de ofrecimiento, siguiendo a Gibson (1979), con que la naturaleza se entrecruza con la actividad humana. Un ejemplo son los cuerpos de agua: en Las Coloradas se recuerda que "había esteros preciosos, el estero Puyehue que le llamábamos nosotros, donde íbamos a lavar ahí los pañales a las guaguas, a buscar el agua que bebíamos, la acarreábamos en bidones, era un estero precioso". El énfasis -como en casi todas las referencias que se hacen al agua- tiene un sentido de usufructo. La naturaleza está allí para su uso. Este énfasis troca su sentido en Milleuco. Allí el etnónimo mismo significa, para los interlocutores, "donde brota el agua". Y se apresuran en subrayar: "El agua es una cosa muy sagrada, tal como brota se puede secar". Si ha de usársela, "tienen que pedir permiso, no llegar y tomar esa agua".

La oposición entre una y otra mirada es la que se da entre el usufructo y la regulación ritual del uso, tradiciones cosmovisionarias inscritas dentro del repertorio de posibilidades desplegado en América Latina (Gudynas 2011). Ambas construcciones devienen de procesos históricos paralelos pero diversos. En un caso, como se ha señalado, se trata de un grupo que procura reorganizar su existencia social en parajes marginales y de relativa inaccesibilidad sobre la base de una tradición cultural indígena donde la comunidad se entiende como parte de un todo; en el otro, es la respuesta al aprisionamiento 


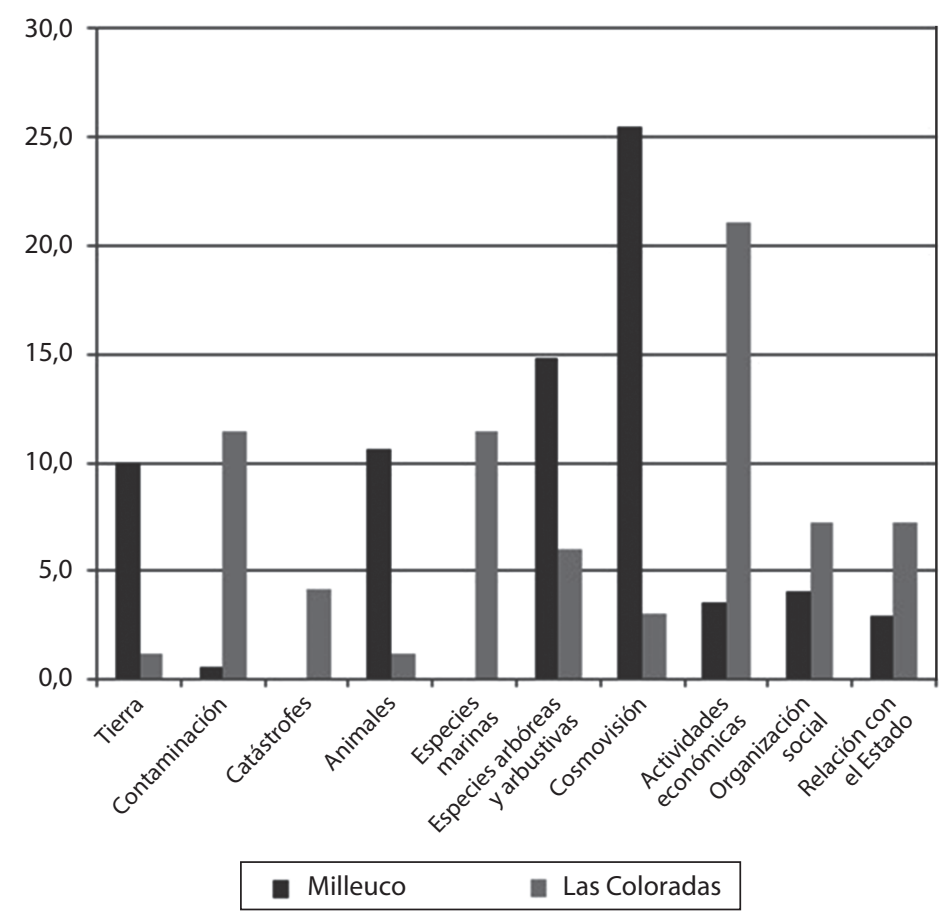

Figura 2. Comparación de hitos temáticos en dos comunidades (expresados en porcentajes respecto del total de referencias a los nodos registrados para cada comunidad) (elaboración propia).

Comparison of themes in two communities (expressed in percentages of total references associated with the nodes identified for each community) (our design).

territorial de un grupo al que se torna cada vez más difícil su reproducción. La cosmovisión local, en este segundo caso, está mucho más cerca de la concepción campesina que concibe la casa (la unidad doméstica) como el centro y entiende su relación con la naturaleza mediante el usufructo y renovación recíprocas (Gudeman 2008). Ambas concepciones de la naturaleza entran en contradicción con aquella que la entienden como un repositorio de recursos disponibles para ser transados en el mercado (Escobar 1999a; Gudeman 2008; Gudynas 2011).

Al especificar los contenidos de las conversaciones se advierte con mayor nitidez la preponderancia de las determinantes rituales y económicas en uno y otro caso. Las Figuras 3 (referencias más frecuentes en la discusión grupal de Milleuco) y 4 (referencias más frecuentes en la discusión grupal de Las Coloradas) dan cuenta de estas variaciones a nivel de las frases y subcódigos empleados: en el caso de la comunidad indígena cordillerana, el $25 \%$ de las referencias dice relación con la cosmovisión y un $20 \%$ menciona las especies arbóreas y arbustivas que, como se verá más adelante, están más relacionadas con la identidad y la práctica ritual que con su significado económico. En Las Coloradas, en cambio, la percepción ambiental de las y los residentes de la comunidad costera chilena se caracteriza por un énfasis en la dimensión de usufructo con la naturaleza: más del 30\% de las referencias se asocian a las actividades económicas y a la contaminación por ellas provocada.

La preponderancia que el utilitarismo comienza a adquirir en la conversación con las y los residentes de Las Coloradas puede ser atribuible a la situación de enclaustramiento y escasez que lleva a privilegiar dimensiones que se tornan cada vez más urgentes para resolver los problemas de la subsistencia. Sin embargo, la ausencia de referencias a la cosmovisión y prácticas rituales da cuenta de la falta de mecanismos culturales que pudieran tener un efecto amortiguador en la relación con el medio, salvo, como se señala más adelante, la recolección de murta (Uñi molinae), donde prevalece la relación de usufructo por sobre la de utilidad. 


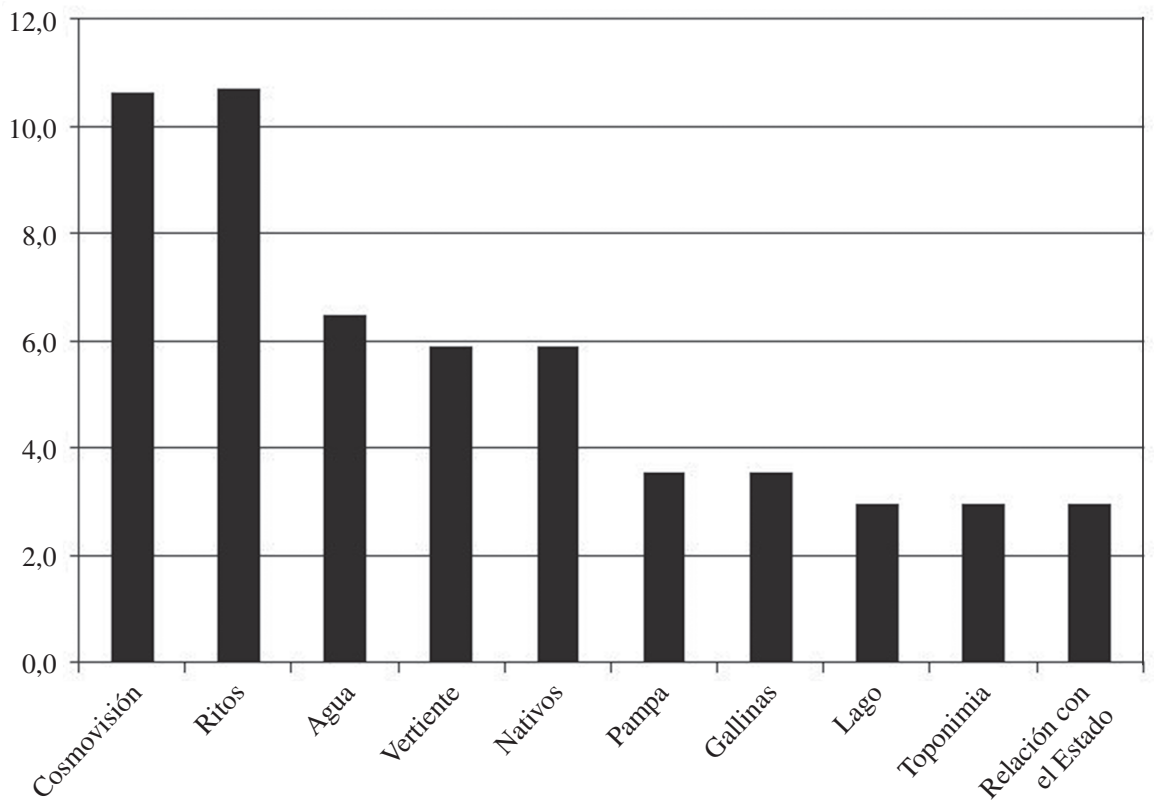

Figura 3. Referencias más frecuentes en la discusión grupal de Milleuco (expresadas en porcentajes del total de referencias a los nodos en la comunidad) (elaboración propia).

Most frequent references in the group discussion in Milleuco (expressed as percentages from the total references to the nodes in the community) (our design).

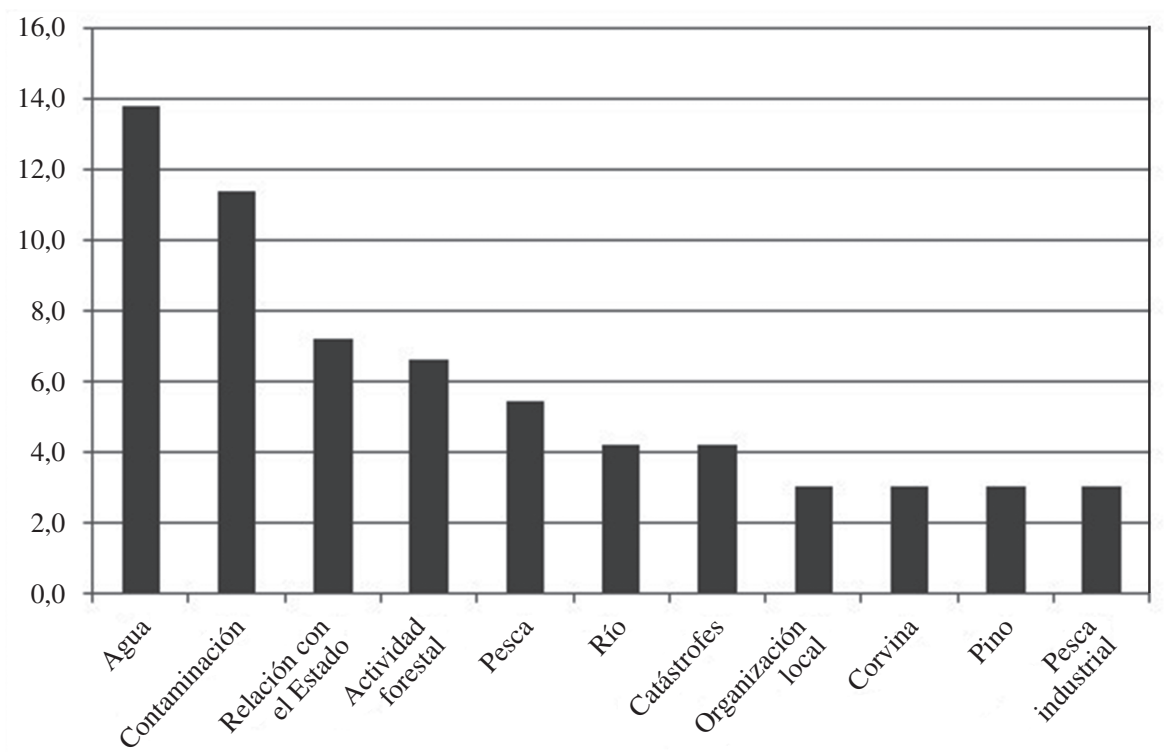

Figura 4. Referencias más frecuentes en la discusión grupal de Las Coloradas (expresadas en porcentajes del total de referencias a los nodos en la comunidad) (elaboración propia).

Most frequent references in the group discussion in Las Coloradas (expressed as percentages from the total references to the nodes in the community) (our design). 
En Milleuco se constata la presencia de una nomenclatura que sacraliza el espacio local y, en la conversación, se multiplican las referencias al complejo ideacional que interrelaciona la cosmovisión con las aguas, vertientes, árboles nativos, la pampa y el lago. Las gallinas que son referidas con mayor frecuencia que otras especies animales son también parte de rituales propiciatorios realizados con motivo de rogativas familiares y ceremonias fúnebres. Solo la relación con el Estado pareciera inmiscuirse en una trama marcada por la relación con la naturaleza, lo cual es sintomático de gestión pública de carácter asistencialista.

En el caso de la comunidad de Las Coloradas se advierte el apremio a que el poblado se somete producto de su creciente aislamiento frente a las actividades de la pesca industrial y de la madera. El agua se torna en el elemento crítico de una relación donde la contaminación vinculada a estas actividades pareciera no encontrar sino en la presencia del Estado alguna oportunidad de amortiguación. Así como la cosmovisión se corresponde con una infraestructura simbólica sobre la que se yergue el edificio cordillerano, aquí la actividad económica industrial marca de manera decisiva la percepción ambiental prevalente en el dominio costero.

Los ejes temáticos en torno a los que se articula la conversación con las y los vecinos de Las Coloradas son la relación con el Estado, los eucaliptus (Eucaliptus globulus), la pesca industrial, y el manejo de residuos. Esta enumeración, fundada en la frecuencia con que los temas son aludidos habla de por sí acerca de una comunidad que se vuelve progresivamente dependiente de su contexto, el que, a la par, resulta amenazante. En un claro contraste, la discusión del grupo de Milleuco tiene otros ejes: laureles (Laurelia sempervirens) y coligües (Chusquea culeou), la presencia de toros (que se identifican con el volcán y que son objeto de los sacrificios rituales), de vertientes, descansos (ritos mortuorios mapuche) y de prácticas rituales. Claramente la comunidad tiene su propio eje y la relación con el medio externo se circunscribe a la mención más esporádica de la oficina especializada que atiende los asuntos indígenas (CONADI).

Más allá de la identificación de las tendencias estructurantes de la percepción local, el análisis de contenido pone de relieve una imbricación más estrecha con los componentes del ecosistema. A fin de dar cuenta de esta relación, se precisa caracterizar la ecología local y, luego, vincular esa caracterización a la construcción simbólica del paisaje. La relación entre los hitos estructurantes de la cosmovisión y la imbricación del ecosistema con la percepción local permite precisar los elementos constitutivos de la identidad colectiva y su asiento en aquellos aspectos del paisaje patrimonializados.

Desde un punto de vista geográfico, costa y cordillera se diferencian por los regímenes de lluvias, por las temperaturas y por la altitud, variables que definen distintos ecosistemas boscosos. En la costa predomina el clima templado cálido lluvioso con influencia mediterránea y su flora se caracteriza por la presencia del bosque laurifolio de Valdivia, con una presencia destacada de especies como el olivillo (Aextoxicon punctatum) y el ulmo (Eucryphia cordifolia). Sus características más favorables de temperatura permiten una mayor diversidad florística (Dirección General de Aguas 2004). La cordillera, en cambio, tiene un clima templado frío lluvioso con influencia mediterránea y bajas temperaturas durante todo el año, aumentando las precipitaciones con la altura. La flora dominante es el bosque caducifolio mixto. En su composición florística intervienen muchas especies típicamente laurifolias: roble-laurel (Nothofagus obliqua - Laurelia sempervirens), roble-mañío de hojas largas (Nothofagus obliqua - Podocarpus saligna), olivillo-laurel (Aextoxicom punctatum - Laurelia sempervirens) y raulí-coigüe (Nothofagus alpina - Nothofagus dombeyii).

Las voces de una y otra comunidad recrean el medio del que son parte, el que, a su vez, es expresión de otras historias de más largo aliento. De hecho, se puede observar una gran diferencia en la composición vegetal en el entorno de cada comunidad. En Las Coloradas, en un radio de tres kilómetros que comprende 2.834 hectáreas es evidente el predominio de especies exóticas de plantaciones forestales. En cambio, considerando el mismo radio, en Milleuco solo un uno por ciento del territorio está destinado a plantaciones exóticas. Desde el punto de vista de la vegetación y la salud del ecosistema boscoso, Las Coloradas presenta una muy baja biodiversidad para el cuidado y protección de sus cuerpos hídricos (ríos y lagos); Milleuco presenta, en cambio, una alta biodiversidad, lo que es beneficioso para la obtención de los servicios ecosistémicos que estos tipos de bosques brindan. Los cuerpos de agua que marcan la existencia de ambas comunidades también expresan la mayor sustentabilidad de Milleuco, dependiente de vertientes 
y esteros, frente a la comunidad de Las Coloradas cuya dependencia de un sistema de mangueras para capturar agua de pozo la torna especialmente vulnerable.

En cuanto al uso del suelo, en Las Coloradas el territorio está dominado claramente por las plantaciones con un 35\% de la superficie, seguidas por bosques de renoval con un $21 \%$ y protecciones con $10 \%$. La pradera ocupa, a su vez, el $9 \%$ de la superficie, las marismas herbáceas un 3\% y el bosque nativo solo un 2\% (Figura 5). La comunidad cordillerana de Milleuco, en cambio, se caracteriza por el predominio de pradera con un $70 \%$ de cobertura en el área considerada (radio de tres kilómetros con relación al poblado). La presencia de bosques de renoval ocupa el segundo lugar con un $29 \%$ de la superficie, mientras el bosque nativo adulto se ubica como tercer uso del área con un $10 \%$. Las plantaciones $(1 \%)$ y matorrales $(0,9 \%)$ son mínimas (Figura 6).

La comparación de la composición y uso de la cobertura vegetal con la percepción local en ambas comunidades pone en evidencia experiencias significativamente diversas que el verbo ha conservado para los habitantes de cada localidad. El análisis de contenido de las transcripciones de las conversaciones sostenidas en una y otra dan cuenta del impacto que estas características del territorio tienen para la subjetividad local, como se aprecia a la hora de identificar especies arbóreas y arbustivas (Figura 7).

Mientras los árboles nativos -y muy particularmente, el roble (Nothofagus obliqua) y el laurel (Laurelia sempervirens) - cobran su lugar en la percepción cordillerana, los pinos (Pino radiata) y las murtas (Uñi molinae) lo hacen en Las Coloradas. La diferencia en uno y otro caso no se refiere tanto al carácter de especie endémica en oposición a especie introducida, sino más bien al carácter sagrado versus el carácter utilitario que se confiere a la naturaleza. El roble (Nothofagus obliqua), en particular, es una especie altamente valorada por su identificación con las personas: hualles, árbol joven en mapuzungun, y pellines, árboles maduros, dan cuenta del tránsito vital hacia la sabiduría que se encarna en los últimos, los viejos robles a quienes había que abrazar para procurar salud y conocimiento. "El laurel, el folle (canelo, Drimys winteri), los árboles son como las personas, nuestros hijos", señala un residente de Milleuco. "El colihue (Chusquea culeou) también es importante, estos no fallan, son los principales cuando se va a hacer un machitún. La gente se preocupa de encontrar un coligüe bueno, largos, bonitos, derechos si es posible. Aquí casi se han terminado los colihues, ahora están volviendo a haber". La murta (Uñi molinae), en cambio, es

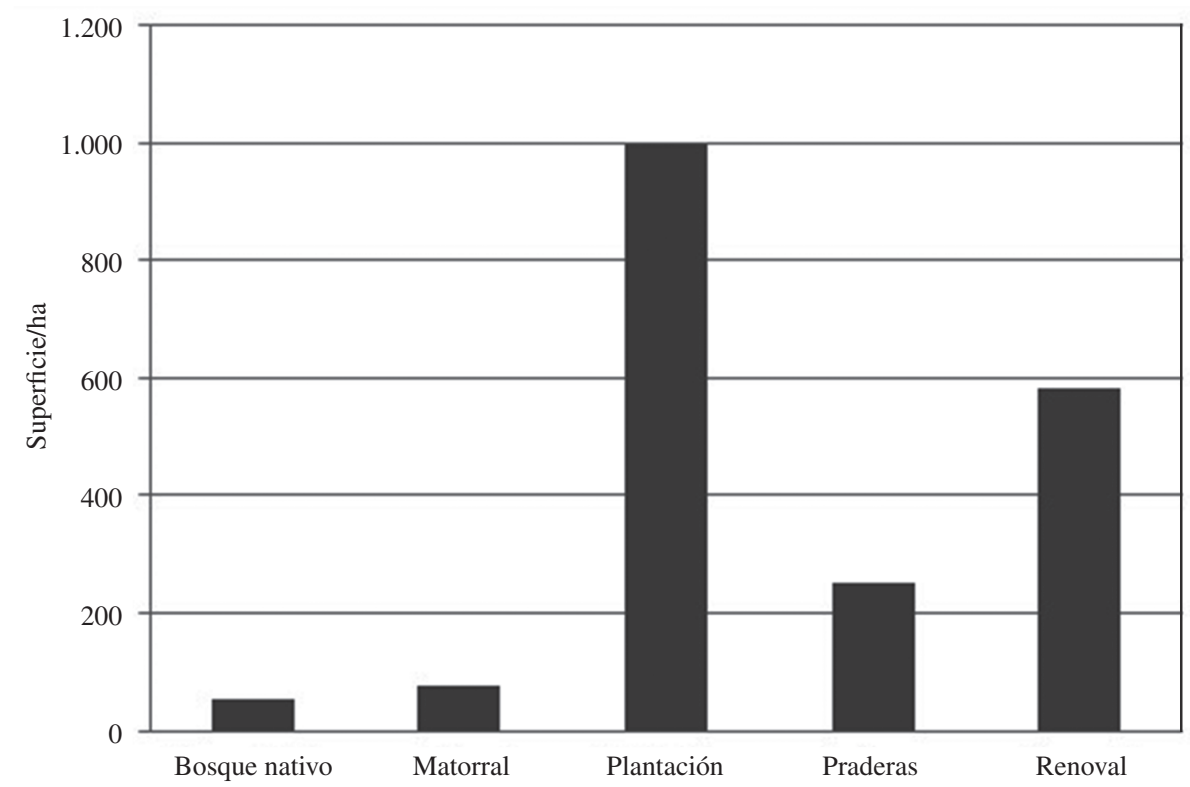

Figura 5. Usos del suelo en Las Coloradas (elaboración propia).

Land use in Las Coloradas (our design). 


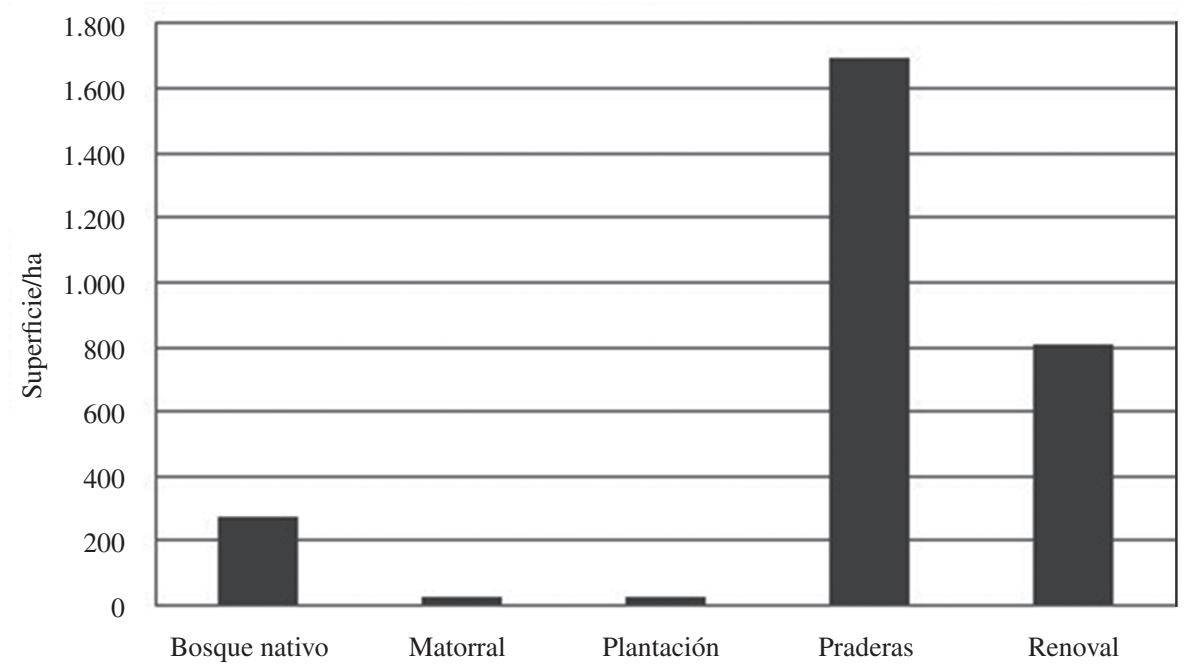

Figura 6. Usos del suelo en Milleuco (elaboración propia).

Land use in Milleuco (our design).

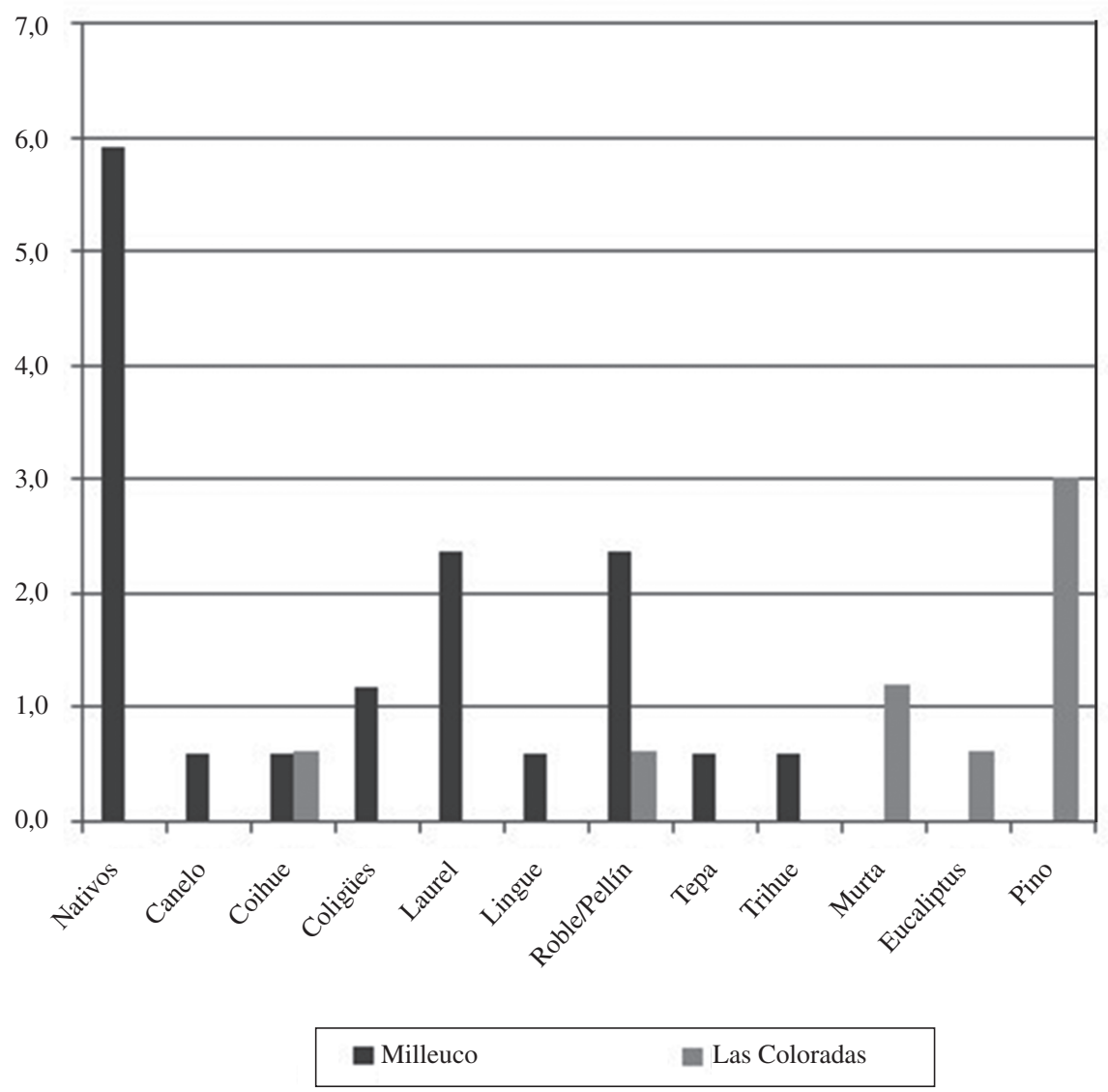

Figura 7. Especies arbóreas y arbustivas en la percepción local (expresadas en porcentajes del total de referencias a los nodos en cada comunidad) (elaboración propia).

Tree and shrub species in the local perception (expressed in percentages from the total number of references to the nodes in each community) (our design). 
objeto de recolección para la comunidad costera para comercializar sus frutos o procesarlos como mermelada para su consumo familiar o venta. Los pinos (Pino radiata), a su vez, son la fuente principal de trabajo en este territorio. La sacralización del entorno confiere ventajas regenerativas para las especies culturalmente estratégicas (Garibaldi y Turner 2004) y bajo un marco utilitario también es posible mantener prácticas sustentables cuando estas tienen un carácter artesanal. Es importante subrayar aquí que la recolección, procesamiento y consumo de la murta (Uñi molinae) son, en efecto, un elemento constitutivo de la identidad local en Las Coloradas. La identidad deviene del vínculo estrecho de la persona y el producto de su trabajo. Sin embargo, la separación radical que un régimen de naturaleza capitalista, siguiendo la terminología de Escobar (1999a) establece entre el trabajador y el objeto de su trabajo es lo que, en definitiva, pone en jaque la resiliencia de las poblaciones y especies locales.

El análisis de contenido da cuenta, en efecto, del empobrecimiento creciente de comunidades como Las Coloradas cuyo posicionamiento se define por la acción extractiva de empresas cuya concepción utilitarista de la naturaleza se centra en la ganancia. Milleuco, en cambio, retiene, a través de su cosmovisión, una relación sacralizada en algunos aspectos con su entorno. Esta naturalmente no es una conducta generalizada o generalizable a toda la comunidad. De hecho las generaciones jóvenes se lamentan de la tala practicada por sus padres para obtener dinero a través de la venta del bosque nativo.

La comunidad de Las Coloradas ha sido clara víctima de los procesos industriales estimulados por el sistema económico. De la larga historia de la comunidad, solamente parecieran prevalecer los impactos industriales que han afectado diversas áreas de la vida local. Forestal Valdivia ha colonizado la Isla del Rey con grandes extensiones de plantaciones de pino (Pino radiata) y eucalipto (Eucalyptus globulus). Esto ha implicado la pérdida de grandes áreas de bosque nativo, el cual ha sido sustituido por especies de rápido crecimiento y de valor económico. Milleuco, en cambio, logró sobrevivir en un área de refugio que, tras sufrir de la explotación maderera del siglo XX, ha visto crecer renovales y recrear paños del bosque nativo de laurel-tepa-roble (Laurelia sempervirens-Laureliopsis philipianaNothofagus obliqua).

\section{Ejercicios de Soberanía}

En los casos discutidos, ies posible hablar de patrimonio? Esto es, ¿es posible pensar que ciertos recursos naturales o culturales pueden constituirse en asiento de la identidad comunitaria? Un altar familiar, un sistema de agua potable rural, ¿son patrimoniales? En una primera lectura ambas prácticas parecieran ser remotas a las inquietudes de los agentes patrimoniales. Difícilmente podría obtenerse una declaratoria de monumento o de sitio de interés para la conservación histórica. ¿Qué es el patrimonio? Desde la perspectiva de los ejemplos citados es engarzar la historia comunitaria en el paisaje local. El patrimonio así entendido es parte de un ejercicio de soberanía que permite inscribir la identidad colectiva en el paisaje. A la luz de esta experiencia resulta claro que si algún aprendizaje cabe desprender de la comparación de estas dos comunidades es la de reconocer prácticas que adquieren un carácter patrimonializador.

En el caso de Las Coloradas, como se ha señalado, la recolección de la murta (Uñi molinae) es también fuente identitaria y, por la escasa presión que su despliegue representa para la especie, puede ser tenida como una práctica cultural que torna sostenible una porción del paisaje. Pero cabe consignar de modo especial lo que los moradores reconocen como el hito principal de la historia comunitaria reciente y que entraña la creación de un bien común: la construcción de una toma de agua y la red de abastecimiento domiciliarios (Figura 8) representó un gran esfuerzo. Se instaló hace 22 años en el único paño de bosque nativo que quedaba en el área: un pequeño boquete de coigüe (Nothofagus dombeyi). Hoy es un orgullo para la comunidad, a la vez que es objeto de preocupación porque el próximo volteo de la Forestal Valdivia implicará la construcción de un camino de un ancho de 12 metros y, con ello, el riesgo cierto que los sedimentos tapen los ojos de agua del estero, disminuyendo la cantidad y calidad del agua para la comunidad.

En Milleuco, en cambio, es posible reconocer varias prácticas que fortalecen un puente material que vincula la identidad local al paisaje de un modo duradero. Por razones de espacio convendrá circunscribirse a solo dos de ellas. Una se relaciona con la historia del paisaje y, la otra, con la conducta observada frente a la naturaleza. Ambas son, en realidad, caras de una misma moneda y tienen efectos patrimonializadores. 


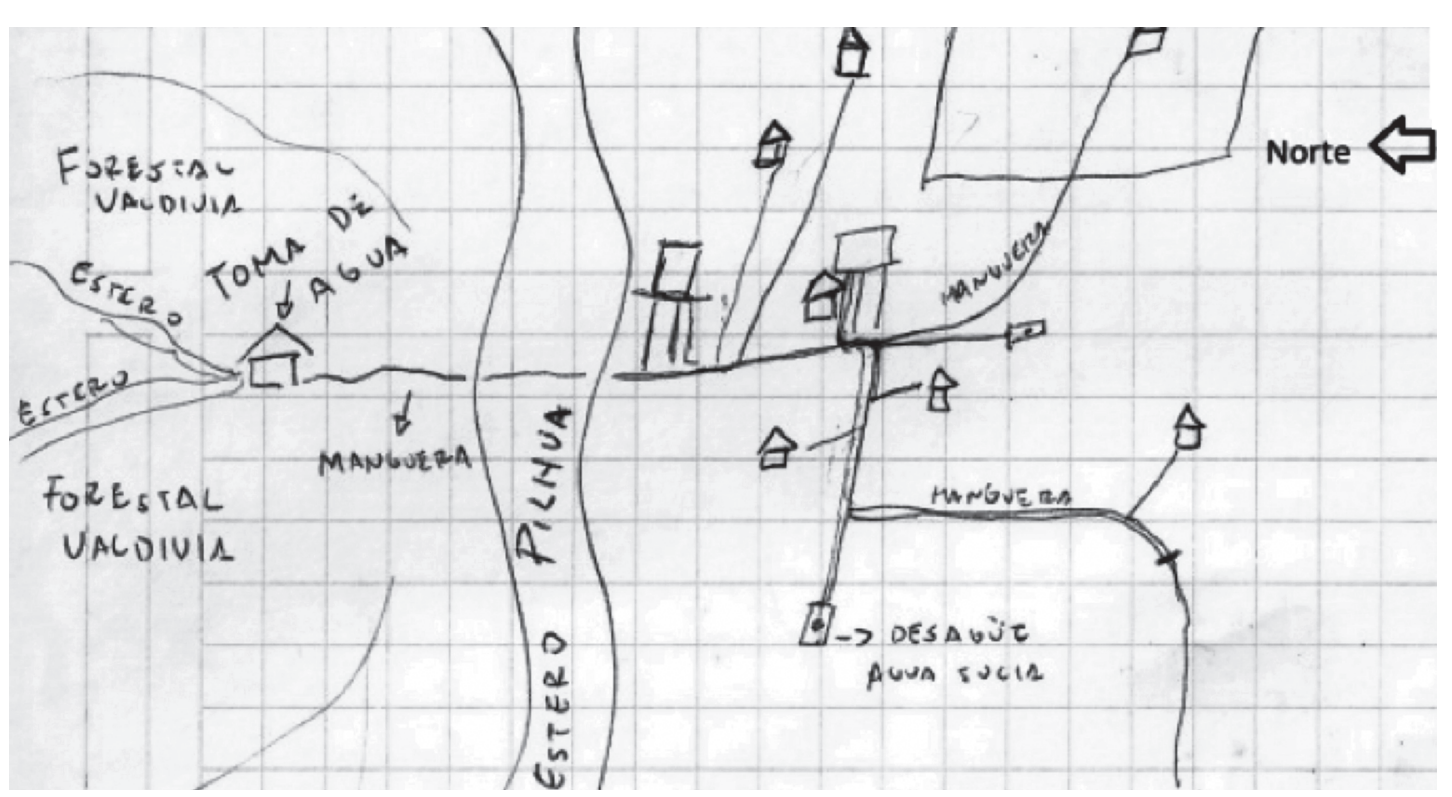

Figura 8. El agua potable rural: un patrimonio fluido (facsímil del dibujo de un residente local).

Rural potable water as a fluid heritage (facsimile of the drawing of a local resident).

Los hitos espaciales que confieren identidad y sirven de asiento a un sentido patrimonial, se relacionan directamente con las características ecológicas del territorio: un estrechamiento de los recursos locales fruto del predominio de plantaciones se traduce en una especialización del vínculo comunidad-paisaje en aquellos ámbitos que se tornan cruciales para la sustentabilidad de la vida local. El agua potable resulta ser el hito identificador que la comunidad tiene como patrimonio. Por el contrario, una abundancia mayor de recursos en términos de bosques y renovales amplía el horizonte de resiliencia para la comunidad, como es el caso de Milleuco donde árboles, cursos de agua y otros componentes del paisaje se prestan para ser habitados por seres espirituales que confieren a la comunidad un asiento patrimonial. En un caso, la estrechez del recurso se asocia indefectiblemente a su agotamiento y pérdida, motivo por el cual se entiende este bien como fungible. En el otro, el hito identitario se integra a un sistema en que se regenera bajo nuevas formas patrimoniales. El caso del rito del descanso, como se describe más abajo, es especialmente relevante para ilustrar este punto.

La inervación persona-comunidad-paisaje es el núcleo básico de una relación que ritualmente se recrea a través de las generaciones. El paisaje de Milleuco es simultáneamente narrado y vivido. Por ejemplo, la relación de los nombres son anclas no menores. "Milleuco es donde brota el agua, las vertientes salen del cerro. Hay parte en donde sale agua de una laderita y así debe ser" y "el agua es una cosa muy sagrada, tal como puede brotar". "Dice la gente que antes los Longko cuando llegaban a una parte que nunca habían ido tienen que pedir permiso, no llegar y tomar esa agua, para ir a poner la primera mano tienen que pedirle al que estaba en el agua (aunque no se viera se sabe que hay un ángel en el agua y es cierto), eso es muy cierto porque aquí mi señora tiene un campito por allá en donde agarraban agua los viejitos. Cuando tocó esa agüita y no quedaba agua, estaba seco. Como yo tengo esa idea le interrogué, le pude hablar a los santos y ahora hay agüita, se mantiene buena agua".

La expresión principal de esta vinculación comunidad-naturaleza queda de manifiesto en la identidad que se crea entre persona y árbol con motivo de la ceremonia del descanso a través de la que se consagra un pequeño altar junto a un árbol, de preferencia un roble, en el linde del predio familiar (Figura 9). La persona en vida solicita que se le construya esta gruta junto a un árbol que, con el paso de los años, recordará su presencia en la comunidad. Para sus descendientes aquel árbol será el asiento de la memoria del abuelo. La persona habrá mutado en árbol y el árbol en parte del paisaje asegurando la continuidad de los recuerdos y de la naturaleza que circunda y hace posible la existencia comunitaria. 


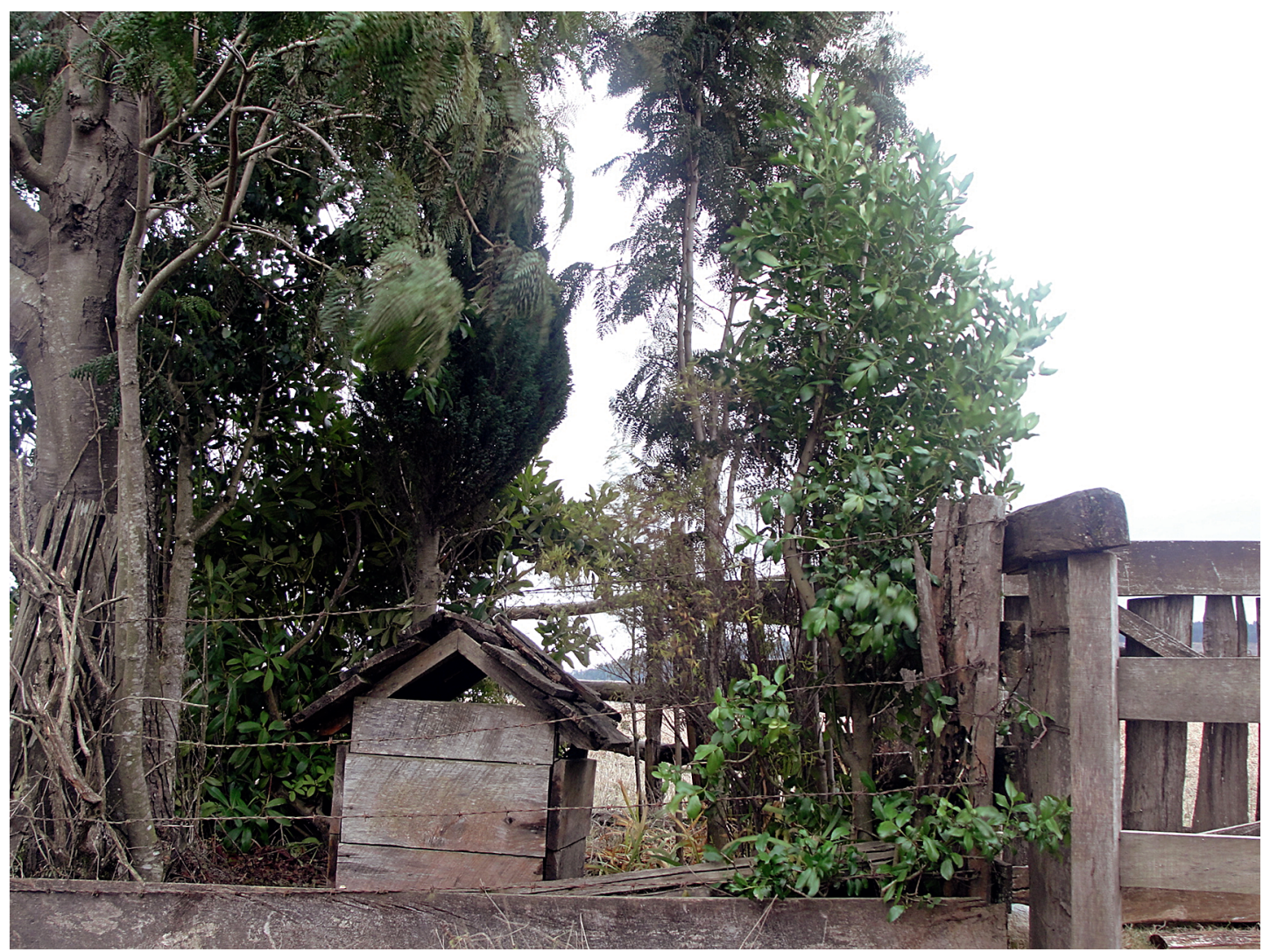

Figura 9. Un descanso en Milleuco (fotografía G. Pacheco).

A descanso in Milleuco (photograph by G. Pacheco).

De acuerdo con lo anterior resulta necesario reconsiderar las formas como los reclamos comunitarios merecen ser formulados, evaluados y resueltos en un contexto de vinculación con el Estado y demás actores de la sociedad global. No cabe, desde este punto de vista, presumir la existencia de definiciones comunes para situaciones similares. Ni siquiera suponer que hay diferencias entre las definiciones que confieren sentido a la relación entre comunidad y naturaleza. El error en las discusiones contemporáneas acerca de la diversidad cultural, según Eduardo Viveiros de Castro (2004), no es solo un problema de entendimiento, sino de entender que los entendimientos no son los mismos y que no se corresponden con distintas maneras de ver el mundo sino que con distintas maneras de ser en el mundo. La función del sector público -y de las propias organizaciones indígenas y comunidades rurales- es conocer, explicitar y definir las condiciones básicas que atañen al ser en el mundo que les es propia en los diversos contextos en que la intersección entre Estado y comunidad tiene lugar. No hay un modo general de asumir tal relación sino un adecuamiento a las circunstancias en que tal entrecruzamiento tiene lugar.

\section{Conclusiones}

Los resultados de esta investigación sugieren que existen prácticas culturales que resultan en el mediano y largo plazo más protectoras respecto de la sustentabilidad de las comunidades, lo que está ampliamente validado en la literatura (ver, por ejemplo, la extensa revisión hecha por Russell et al. [2013]). Estas prácticas merecen ser evaluadas en sus propios términos y no puede generalizársela a todo un grupo. No cabe, en este sentido, pensar que un grupo pueda ser más sustentable que otro, sino más bien que existen prácticas cuyo carácter permite una mayor protección de los recursos locales. Tales prácticas se asocian con una percepción que, en su despliegue, se expresa en un vocabulario más rico 
en cuanto a su diversidad y en un reconocimiento de una pluralidad de funciones asociadas con la naturaleza circundante.

La exploración de los contenidos de las conversaciones en las comunidades chilena e indígena de la cuenca del río Valdivia da cuenta del impacto que la naturaleza circundante ejerce en la organización de la infraestructura simbólica en que se asienta la vida local. Las relaciones que se producen entre el habla y el ambiente se sintetizan en la práctica que remodela el paisaje, la cual está condicionada por procesos que escapan al control local. Así, a pesar de los esfuerzos de los actuales habitantes de Las Coloradas, el proceso a que son expuestos por la intrusión de actividades extractivas induce un progresivo decaimiento y, a juzgar por la decreciente matrícula escolar en los últimos años, es probable que la comunidad termine por disolverse. Lo vivido corresponde a un proceso de despatrimonialización donde se conjugan la presencia colonizadora de los monocultivos con una ideología y una cosmovisión profundamente marcada por el lucro. La mitología local es testimonio de este doble juego en que naturaleza y cultura se entrelazan en formas autodestructivas: la imagen de cerros horadados por un buscador de tesoros es la más elocuente para ilustrar la existencia de estos paisajes terminales. La erosión de la naturaleza y la erosión de los sentidos se retroalimenta al punto de su extinción.

La comunidad de Milleuco, alentada por otra filosofía y nutrida por una naturaleza diversa puede reinventarse en su territorio. Sus prácticas rituales, aunque no declaradas, son patrimonializadoras, toda vez que engarzan la historia comunitaria y personal en el paisaje al que nutren y del que se nutren.

La comparación de los contenidos conversacionales en dos comunidades rurales dan cuenta del efecto patrimonializador que las prácticas culturales pueden tener, entendiendo este efecto como la capacidad de perseverar con una identidad engarzada en un entorno que provee de los medios para simultáneamente recrear el paisaje propio y sustentar la trayectoria socioambiental de la comunidad. Se logra por esta vía identificar la infraestrutura simbólica que sostiene condiciones de habitabilidad tanto para seres humanos como no humanos. Dado que en su historicidad cada comunidad es única, los hitos o ejes articuladores de la historia son diversos, de modo que se precisan formas de objetivar el balance en términos comparativos. El análisis simultáneo de los contenidos de las conversaciones con las características ecológicas del territorio permite alcanzar este propósito.

Desde el punto de vista del desarrollo del conocimiento, ambas experiencias son paradigmáticas y merecen ser consideradas para los fines de una mejor comprensión de los procesos patrimoniales. Enseñan a ejercer una cierta modestia respecto de la naturaleza -a saberse parte de ella, a saber que inevitablemente la acción humana es naturaleza en transformación-y, respecto del patrimonio, más que de declaratorias, son las prácticas las que merecen entenderse como patrimoniales. La conversación con el difunto a la sombra de un roble o de un laurel o la celebración de una rogativa familiar al comenzar el día, la atención prestada al canto y al vuelo de las aves, nombrar las cosas del mundo, pueden ser ejercicios más significativos que la declaratoria de este monumento o aquella práctica como patrimonial. De ello se desprende que la protección del patrimonio pasa por asegurar las condiciones para que aquellas prácticas puedan seguir siendo.

Los desarrollos contemporáneos de estas líneas de investigación han derivado en la formulación tanto de una ecolingüística (Basso 1996) como de una ecología simbólica (Descola 2013). Ambas líneas han transitado por vías paralelas y no deja de ser interesante reconocer la carencia de estudios que vinculen ambas perspectivas. Desde este punto de vista, la presente investigación puede considerarse como un puente que permite vincular procesos políticos que transforman el paisaje local con el procesamiento simbólico y cognitivo de tales procesos por parte de los actores locales.

La oportunidad de producir un punto de encuentro entre la ecología política y la ecología simbólica representa un recurso que, para fines de la planificación, es necesaria e inédita. En efecto, la revisión de los estudios concernientes a la relación entre paisaje y bienestar ponen de relieve la ausencia de investigaciones que den cuenta de las diversas formas de experimentar la naturaleza y el bienestar humano, y, en particular, los vínculos entre identidad, autosuficiencia y sentido de pertenencia en relación con la naturaleza percibida (Russell et al. 2013). Esta constatación no solo es reafirmada por la presente investigación, sino que además su explicitación desborda con mucho los estrechos márgenes tanto políticos como ideológicos y territoriales en el que el tema de los derechos de los pueblos originarios ha sido situado. Al destacar 
los vínculos que se producen entre autonomía, paisaje y percepción se generan condiciones para una planificación territorial fundada en los aspectos más sustantivos de la vinculación entre un grupo humano y la naturaleza y, por lo tanto, se abren posibilidades para hacer ejercicios culturalmente pertinentes y políticamente flexibles de soberanía en los espacios locales: lugarizar el mundo, como lo sugiere Basso (2006), es una forma de construir historia, de inventarla y de crear nuevas maneras de entender lo que allí ocurrió y de visualizar un mejor futuro para quienes la rehacen en lo cotidiano.

Agradecimientos: El presente artículo se inscribe en el marco de los proyectos de investigación
Fondecyt F-1090465 y F-1120139. Quisiéramos agradecer a las y los miembros de las comunidades de Las Coloradas y Milleuco quienes consintieron en participar de las actividades a partir de las que se generó la información sometida a análisis. Finalmente, quisiéramos reconocer la participación de Camilo Avendaño, estudiante de antropología, Rodrigo Cuevas, estudiante de arquitectura, Guillermo Pacheco, estudiante de Turismo, y de Romina Novoa, estudiante de Ingeniería en Recursos Naturales, todos de la Universidad Austral de Chile, quienes fueron activos integrantes del equipo de investigación. De modo especial se agradece a quienes revisaron este artículo y cuyas observaciones resultaron valiosas para la redacción del documento final.

\section{Referencias Citadas}

Bachelard, G. 2003 [1942]. El Agua y los Sueños. Ensayo Sobre la Imaginación de la Materia. Traducido por I. Vitale. Fondo de Cultura Económica, México.

Basso, K.H. 1996. Wisdom Sits in Places: Landscape and Language Among the Western Apache. University of New Mexico Press, Albuquerque.

Biersack, A. 1999. From the "new ecology" to the new ecologies. American Anthropologist 101:5-18.

Bonfil Batalla, G. 1991. Pensar Nuestra Cultura. Alianza, México.

Clifford, J. 1997. Routes: Travel and Translation in the Late Twentieth Century. Harvard University Press, Cambridge, Massachussets.

Criado, F. 1999. Del Terreno al Espacio: Planteamientos y Perspectivas para la Arqueología del Paisaje. Grupo de Investigación en Arqueología del Paisaje. Universidad de Santiago de Compostela, Santiago de Compostela.

De Certeau, M. 1984. The Practice of Everyday Life. Traducido por S. Rendall. University of California Press, Berkeley.

Descola, P. 2013. Beyond Nature and Culture. Traducido por P.J. Lloyd. University of Chicago Press, Chicago.

Díaz, A. 2006 [1907]. El Parlamento de Coz-Coz. Serindígena Ediciones, Valdivia.

Dirección General de Aguas 2004. Cuenca del río Valdivia. Diagnóstico y clasificación de los cursos y cuerpos de agua según objetivos de calidad. Ministerio de Obras Públicas, Santiago. (diciembre) www.sinia.cl/1292/articles-31018_Valdivia.pdf (6 abril 2012).

Escobar, A. 1998. Whose knowledge, whose nature? Biodiversity, conservation, and the political ecology of social movements. Journal of Political Ecology 5:53-82.

----1999a. El Final del Salvaje. Naturaleza, Cultura y Política en la Antropología Contemporánea. CEREC, Santafé de Bogotá. ----1999b. After nature. Steps to an antiessentialist political ecology. Current Anthropology 40:1-30.

Farina, A. 2000. The cultural landscape as a model for the integration of ecology and economics. Bioscience 50:313-320.

Garibaldi, A. y N. Turner 2004. Cultural keystone species: Implications for ecological conservation and restoration. Ecology and Society 9, 1. (31 diciembre). http://www.ecologyandsociety. org/vol9/iss3/art1 (30 abril 2012).

Gibson, J.J. 1979. The Ecological Approach to Visual Perception. Houghton Mifflin, Boston.

González Cruz, F. 2004. Lugarización, globalización y gestión local. Polis. Revista On-Line de la Universidad Bolivariana 7. (16 enero 2012). http://www.revistapolis.cl/7/gonz.htm (30 abril 2012).

Gudeman, S. y A. Rivera 1990. Conversations in Colombia: The Domestic Economy in Life and Text. Cambridge University Press, Cambridge, New York.

Gudynas, E. 2011. Imágenes, ideas y conceptos sobre la naturaleza en América Latina. En Cultura y Naturaleza, editado por L. Montenegro, pp. 267-294. Jardín Botánico de Bogotá, José Celestino Mutis, Bogotá.

Guerra, D.E. y J.C. Skewes 2008. ¿Vernaculización, hibridación, enajenación o patrimonialización? Disyuntivas locales en la construcción del paisaje. Conserva 12:5-37.

Hastrup, K. 2009. Waterworlds: framing the question of social resilience. En The Question of Resilience: Social Responses to Climate Change, editado por K. Hastrup, pp. 11-30. R. Dan. Academy Sci. Lett, Copenhagen.

Hymes, D. 1972. The ethnography of speaking. En Anthropology and Human Behavior, editado por T. Gladwin y W. Sturtevant, pp. 15-53. Anthropol. Soc. Wash, Washington, DC.

Ingold, T. 1993. Globes and spheres. The topology of environmentalism. En Environmentalism. The View from 
Anthropology, editado por K. Milton, pp. 31-42. Routledge, London, New York.

----2011. Being Alive: Essays on Movement, Knowledge and Description. Routledge, London, New York.

Instituto Nacional de Estadísticas 2013. Estadísticas Demográficas y Vitales. (diciembre). http://www.ine.cl/canales/chile_estadistico/ demografia_y_vitales/demografia/demografia.php (6 agosto 2013).

Krippendorf, K. 1990. Metodología del Análisis de Contenido. Paidós, Barcelona.

Latour, B. 1999. Pandora's Hope. Essays on the Reality of Science Studies. Harvard University Press, Cambridge, Massachussets.

Leff, E. 2003. La ecología política en América Latina: un campo en construcción. Sociedade e Estado 18:17-40.

Massey, D. 2005. For Space. Sage, London.

Millanguir, D. 2007. Panguipulli Historia y Territorio 18501946. Imprenta Austral, Valdivia.

Mülhaüsler, P. y A. Peace 2006. Environmental discourses. Annual Review of Anthropology 35:457-479.

Naciones Unidas 1992. Convenio Sobre La Diversidad Biológica. (3 febrero). www.cbd.int/doc/legal/cbd-es.pdf (14 noviembre 2013).

Nazarea, V.D. 2006. Local knowledge and memory in biodiversity conservation. Annual Review of Anthropology 35:317-335.

Orlove, B. y S.C. Catton 2010. Water sustainability: anthropological approaches and prospects. Annual Review of Anthropology 39:401-415.

Ortner, S. 1984. Theory in anthropology since the sixties. Comparative Studies in Society and History 26:126-166.

Rehren, O. 1908. Memoria de la Inspeccion Jeneral de Colonizacion e Inmigracion. Imprenta i Encuadernacion de S.A. Garcia Valenzuela, Santiago.

Rivas, R. 2006. Desarrollo Forestal de Neltume: Estado y Trabajadores (1924-1990). Tesis de Grado. Facultad de Filosofía y Humanidades, Universidad Austral de Chile, Valdivia.

Rosaldo, R. 2000. Cultura y Verdad: Nueva Propuesta de Análisis Social. Traducido por J. Gómez. Ediciones Abya-Yala, Quito.
Rozzi, R. 1997. Hacia una superación de la dicotomía biocentrismoantropocentrismo. Ambiente y Desarrollo 13: 80-89. (marzo 2011). www.cipma.cl/web/200.75.6.169/RAD/1997/3_Rozzi. pdf (6 marzo 2012).

Russell, R., A.D. Guerry, P. Balvanera, R.K. Gould, X. Basurto, K.M.A. Chan, S. Klain, J. Levine y J. Tam 2013. Humans and nature: How knowing and experiencing nature affect well-being. Annual Review of Environment and Resources 38:473-502.

Skewes, J.C., D. Guerra, P. Rojas y M.A. Mellado 2011. ¿La memoria de los paisajes o los paisajes de la memoria? Los enigmas de la sustentabilidad socioambiental en las geografías en disputa. Desenvolvimento e Meio Ambiente 23:39-57.

Skewes, J.C., M.E. Solari, D. Guerra, y D. Jalabert 2012. Los paisajes del agua: naturaleza e identidad en la cuenca del río Valdivia. Chungara Revista de Antropología Chilena 44:299-312.

Strang, V. 2006. Substantial connections: water and identity in an English cultural landscape. Worldviews: Environment Culture Religion 10:155-177.

Subiabre, A., C. Varela y M.E. Gómez 1997. Análisis Geográfico de Corral. Proyecto de Investigación I-77-87. Facultad de Ciencias, Universidad Austral de Chile, Valdivia.

Tuan, Y.-F. 1974. Culture, Experience, and Environmental Attitudes. Columbia University Press, New York.

Vessuri, H. 2004. La hibridización del conocimiento. La tecnociencia y los conocimientos locales a la búsqueda del desarrollo sustentable. Convergencia. Revista de Ciencias Sociales 35:171-191.

Viveiros de Castro, E. 2004. The transformation of objects into subjects in Amerindian ontologies. Common Knowledge 10:463-484.

Wolf, E.R. 1982. Europe and the People Without History. University of California Press, Berkeley.

Zimmerer, K. 2003. Just small potatoes (an ulluco)? The use of seed-size variation in "native commercialized" agriculture and agrobiodiversity conservation among Peruvian farmers. Agriculture and Human Values 20:107-123.
1 Para los efectos de la información el trabajo fue dividido en organización e implementación de las entrevistas en recopilación profundidad, además de la construcción de las categorías (D. Guerra), dirección de los grupos de discusión y redacción del texto (J.C. Skewes) y realización de recorridos comentados y aplicación de los códigos (Ch. Henríquez), pero, naturalmente, en la realización de los terrenos, redacción de texto y actividades conexas participó todo el equipo de trabajo.

Las reuniones grupales se organizaron con la colaboración de las organizaciones locales y la participación en ellas fue voluntaria. El grupo de Milleuco estuvo compuesto de cinco hombres y dos mujeres, todos de origen mapuche. Entre los hombres se contó con dos adultos mayores y tres adultos jóvenes; las mujeres que asistieron eran ambas adultas. Todos los participantes del grupo eran residentes permanentes de la localidad. En Las Coloradas se contó con la participación de nueve personas, seis mujeres y tres hombres, todos adultos. Entre los participantes se contaban la Presidenta del Comité de Agua Potable Rural y el Presidente de la Junta de Vecinos. $\mathrm{El}$ formato fue de conversación libre y el equipo investigador se abstuvo de intervenir en el diálogo salvo para presentarse y formular preguntas en los momentos que se estimó oportuno. El tema general de la reunión lo constituyó el agua por el carácter estratégico que este elemento tiene para la vida local. Como lo subrayan Orlove y Catton (2010) el agua trasciende con mucho los usos agrícolas, circula prácticamente por todos los dominios de la existencia social y es administrada de modo diverso según quien lo haga sea hombre o mujer, siendo crucial en áreas como la industria, la generación de energía, la pesca, el turismo, los deportes, amén de su consumo tanto básico como conspicuo. Simultáneamente, el agua atrae un denso simbolismo en las diversas poblaciones humanas, tal como lo sugiere 
Bachelard (2003 [1942]). Hastrup (2009) ha sugerido el concepto de mundo hidromundo (waterworld) para referirse a la totalidad de conexiones sociales, culturales, políticas, técnicas y económicas involucradas en el agua.

El plan de análisis se basó en los criterios convencionalmente establecidos para estos efectos. Se entiende el análisis de contenidos como "la técnica destinada a formular, a partir de ciertos datos, inferencias reproducibles y válidas que puedan aplicarse a un contexto" (Krippendorff 1990:28). De acuerdo como sugiere este autor, es preciso considerar en la aplicación de este procedimiento los datos tal y como se comunican al analista, el contexto en que se generan, y la forma en que el conocimiento del analista invita a dividir la realidad. En la investigación cualitativa, este proceso tiene un carácter emergente, abriéndose las categorías del análisis a las posibilidades que la información de campo provee. 